\title{
CONSCIOUSNESS AND THE END OF MATERIALISM: SEEKING IDENTITY AND HARMONY IN A DARK ERA
}

\author{
Ph.D. Spyridon I. KAKOS \\ National Technical University of Athens (NTUA), Athens, \\ GREECE \\ Email: skakos@hotmail.com
}

\begin{abstract}
"I am me", but what does this mean? For centuries humans identified themselves as conscious beings with free will, beings that are important in the cosmos they live in. However, modern science has been trying to reduce us into unimportant pawns in a cold universe and diminish our sense of consciousness into a mere illusion generated by lifeless matter. Our identity in the cosmos is nothing more than a deception and all the scientific evidence seem to support this idea. Or is it not? The goal of this paper is to discard current underlying dogmatism (axioms taken for granted as "self-evident") of modern mind research and to show that consciousness seems to be the ultimate frontier that will cause a major change in the way exact sciences think. If we want to re-discover our identity as luminous beings in the cosmos, we must first try to pinpoint our prejudices and discard them. Materialism is an obsolete philosophical dogma and modern scientists should try to also use other premises as the foundation of their theories to approach the mysteries of the self. Exact sciences need to examine the world with a more open mind, accepting potentially different interpretations of existing experimental data in the fields of brain research, which are currently not considered simply on the basis of a strong anti-spiritual dogmatism. Such interpretations can be compatible with the notion of an immaterial spirit proposed by religion for thousands of years. Mind seems that is not the by-product of matter, but the opposite: its master. No current materialistic theory can explain how matter may give rise to what we call "self" and only a drastic paradigm shift towards more idealistic theories will help us avoid rejecting our own nature.
\end{abstract}

Keywords: mind; brain; materialism; consciousness; dogmatism; axioms; neuroscience;

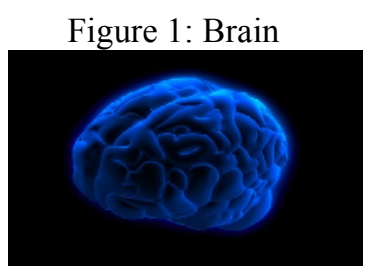

\section{INTRODUCTION}

In a recent research, scientists found out that the human brain could store ten times more memories than previously thought (according to models used by scientists based on rat brains) ${ }^{[1]}$. The news was re-posted by various prestigious science portals, one of them being Popular Science ${ }^{[2]}$. Reading this headline and skimming through the article makes someone very happy to know that scientists are starting to understand more and more things about the brain and its processes. Science is really living the dream of increasing knowledge and at the end everything will be revealed. This kind of optimism runs through all brain research. And 
yet, a small 'footnote' mentioned in the article points us towards a well-hidden secret. In that footnote it is mentioned that scientists claim things about the memory capacity of the brain even though they "still don't understand much of how they work, including how their size affects how information is transmitted or stored in the brain" (sic). So, to put it simply: we have created models to analyze the brain, but we do not know how and even if these models work like brain works. And yet, based on these models we make predictions and draw conclusions. This is unfortunately not an isolated incident. Researchers across the world are usually equally blunt into supporting a materialistic notion of consciousness even though our understanding of the brain does not support such a notion. For example, research related to reading the brain signals and controlling e.g. a machine ${ }^{[3]}$, is often portrayed as direct evidence that what we feel as 'consciousness' is nothing more than an elaborate illusion generated by simple brain signals generated by cells.

Such research is conducted in the context of a sector of science called "neuroscience", which for many years now tries to solve the mystery of human consciousness. Even though there is great progress in the analysis of the mechanisms of our brain, the key to human consciousness remains well hidden. "At least for now", some scientists say, thus alleviating any worries that science might never reach to the conclusions already promoted as 'true' by the proponents of materialism. That belief that we will someday explain the very nature of our identity based on our current models would be romantic at least, if it was not a showcase of blunt dogmatism as well: All these scientific efforts to understand the 'final frontier' regarding the reality of who we are, are based on specific axioms (materialism, mechanistic view of the cosmos, reductionism) which are promoted as self-evident truths, instead of arbitrarily chosen starting points. And none of these axioms leave any space for us (conscious humans) in the cosmos. The fact that modern science cannot discover consciousness is not a temporary gap of knowledge, but more of the result of specific principles on which science is currently based. We have created a universe void of humans and now we are surprised we cannot find humans in it.

This paper does not attempt to offer an exhaustive record of all knowledge existing concerning the human mind, but rather to provide some insight on why the explanation of human consciousness lies beyond the limits of exact science as it is currently based on the abovementioned axioms. It is shown that only a drastic paradigm-shift of science away from the materialistic view of the cosmos can help us truly understand the nature of what seems to make us who we really are. My identity as a human being is something which cannot be reduced to a set of lifeless particles and any attempt to come in harmony with our true nature passes through a drastic change in our way of thinking.

Electrons and electromagnetic fields race through our brain. Is that "consciousness"? Or is consciousness controlling those electrons?

\section{WHY NEUROSCIENCE WILL NEVER EXPLAIN CONSCIOUSNESS}

Some scientists today believe that they can explain the mind by just analyzing the mechanisms of the brain. They seem to believe that by finding how neurons interact with each other will lead them to fully understand the nature of human consciousness. This view is based on the principles (axioms) of materialism and reductionism (and up to a point to the mechanistic view of the cosmos as well): The cosmos is made up of matter and everything 
can be reduced to explanations based on (mechanistic) interactions of that matter ${ }^{1}$. And it is the main purpose of true philosophy to find, pinpoint and show the underlying axioms of all views, criticize them, discuss them and potentially try new ones to discover new paths of knowledge. This section contains a list of arguments that show why human consciousness cannot be explained by merely explaining the chemical-physical mechanisms of neuron activity in our brain. A short basic epistemological note seems necessary at this point: Every scientific theory is based on some foundations, called axioms (or principles). Those axioms are - by definition - not proved; they are just taken for granted in order to start creating a theory. That does not mean that the theory is necessarily wrong - just that it cannot be proven beyond the shadow of a doubt based on our current scientific way of thinking. Every theory must be based on something and that creates inherent limits to the validity claims the theory can make. Gödel's incompleteness theorem cast the last stone upon the now disproved idea of proving anything, so we must all be aware of those limitations when talking about "proofs". In any case, the only thing we can do is to question the existing axioms and try to formulate new theories based on new ones. We will be surprised to see that those theories can be as "correct" as the old ones. This is not something bad or wrong. It is just the way science works.

Discarding the long-held belief that current neuroscience will explain everything concerning consciousness - the very thing which determines our identity - is of extreme importance if we are to start investigating other paths to interpreting reality; a reality which for thousands of years included the one thing which modern science does not want to hear about: immaterial spirit.

\subsection{Finding correlations does not mean we understand mind or consciousness}

There is a deeper problem concerning the human consciousness. It may be that the subjectivity of consciousness and the lack of a formal definition do not prevent neuroscience from finding the "Neural Correlates of Consciousness" (also known as NCC). But what does it actually mean to find these correlates is a whole different matter. Ideally, neuroscience should explain facts about consciousness in terms of facts about the neural activity. If not, then we are only rationally justified in believing that brain and mind are somehow correlated, but not that human consciousness is in fact a wholly natural phenomenon ${ }^{[4,5]}$. Christof Koch, a professor of biology and engineering at the California Institute of Technology, seeks those neural correlates; something which generally means the kinds of electrical activities that occur in the brain each and every time that a certain conscious experience occurs. Koch has made the neural correlates of consciousness real science by bringing progressively greater precision to assessing what is happening in the brain, in real time, when subjective experiences are sensed or felt. But it important to note that correlation is not cause, as Koch correctly points out. And the correlations so far describe specific sensations, not a unified consciousness ${ }^{[6]}$. The difference is important to note. It is a mistake to confuse one thing for another: many things can be interconnected but that does not automatically create a cause-effect relationship between them (if causality exists at all, but this is a greater philosophical problem out of the scope of this paper). The so far correlations found do not prove anything concerning the true nature of consciousness; where "true

\footnotetext{
${ }^{1}$ The problem of the definition of what "matter" actually is, is another important aspect which is outside of the scope of this paper. Even though many people believe that matter is well defined, it is not: particles seem to be waves of energy which materialize upon observation or interaction with something else and science is still searching the basis of matter (e.g. Higgs boson).
} 
nature" mainly refers to the way we feel we are "we" in our everyday lives. We are still far away from knowing what the cause of consciousness is, let alone say that it is only a "natural" cause based on electricity currents. Confusing correlation with cause is a "mistake" or - even worse - an offspring of hard materialistic dogmatism.

After all, who can say that a thought is made up of electrons without challenging his logic? For example, can the thought "the circumference of a circle is equal to $2 \pi r$ " be made up of electricity? Thinking of thought as a set of things or objects is a categorical error. It is something "that it is not even an error", as Pauli used to say when a student of his presented an idea that was completely off the scope of the question asked. Is a thought made up of something material and if yes, how can that be? In what sense does that make sense? Electrons are electrons. Neurons are neurons. A thought is a thought and cannot be made of the abovementioned materials, simply because thought is something inherently different than these "things". Many electrons form "many electrons", not a human "thought". The words in this document - either on paper or in 01 's in computer's memory - mean nothing except for a human who reads them. It is common for scientists to say "This has no meaning" when presented with metaphysical questions (try to ask "What existed before the universe existed?" for example). Could we be trying to answer similar meaningless questions by making connections that simple are not there in the first place?

\section{The TV analogy example}

A good example of how our theories about the brain might be wrong is the TV analogy: Look at the TV in your home. It seems that it generates the TV show you watch. Every empirical data you have, point towards this direction. Try to examine the inside of the television and you will see that its circuits indeed fire up and "do something" as the image you see is generated. What more proof would you need, right? What is more, when the TV breaks, the image stops. In the same way humans are being left unconscious when their brain is damaged (by the way one of the most - supposedly - compelling arguments in favor of the brain as generator of 'consciousness'). And yet, in reality, the image you see in the TV is not generated by the TV; it is just received by it. Correlation does not mean anything besides what it is: correlation. Expanding this into other conclusions is risky and sometimes even unscientific - at least when this is done without a strong disclaimer.

\subsection{The mind is more than the sum of the brain cells (why reductionism is wrong)}

David Chalmers, an Australian philosopher of mind, claims that consciousness is not an accidental derivative of reality working randomly but a fundamental part of reality existing permanently. For decades, there had been a progressive demystification of consciousness. But for Chalmers no matter how much neuroscience we learn, we will never explain consciousness. No matter how good the correlations of brain to mind are, they could never literally be "mind". It seems that there must be something extra in consciousness, which can never be explained by anything physical, chemical, or biological (at least in the way those terms are defined today) ${ }^{[7]}$. Neuroscience is inherently reductionist, since it plans to solve the problem of consciousness by finding its physical substrate and reducing every function of the mind to interactions on that substrate. But this method is hopelessly flawed, and for a simple reason: self-consciousness, at least when felt from the inside, feels like more than the sum of our brain cells' activity (which in any case "feel" nothing on their own). Even if brain plays a role as a substrate, this may mean nothing for the actual state of being conscious (in the same way that buying a new TV means nothing regarding to your 
favorite shows, which are still there being broadcasted, same and unchanged). Any explanation of our experience solely in terms of our neurons will never explain our experience, because we do not experience our neurons but something more. To believe otherwise is to indulge in a simple categorical mistake ${ }^{[8]}$. And again, not knowing exactly what that "something more" is does not nullify its existence. Our experience of us being "us" is something we experience every day and which transcends the sum of each individual neuron activity, something more than the experience of electrical current passing through neuron connections. If we believe what neurologists say, we could have a Printed Circuit Board "feeling" and realizing "itself" like we do. However, a PCB cannot "feel" and cannot have a consciousness, for the same reason that a stone - no matter how well it is designed or how complicated its molecular structures are - cannot have "life" in it. If complexity alone is the generator of the illusion of consciousness, then even the Internet's World Wide Web itself should have experienced "consciousness" a long time ago. You cannot explain apples with oranges. No matter how many oranges you analyze.

\subsection{Neuroscience only explains things defined in functional terms, but consciousness cannot be given a functional definition}

Neuroscience is very useful and can of course be used to explain many things. For instance, memory performance in sea slugs can be explainable in terms of synaptic strength and gene expression. But it seems that only things defined in functional terms can be explained (e.g. the neural mechanism that explains memory function). The problem presented is then the following: consciousness cannot be given a functional definition ${ }^{[5]}$. This means that essentially its true nature cannot be (fully) neuro-scientifically explained.

Assume for a moment that we have discovered all the neural mechanisms that exist. These mechanisms will explain a whole set of psychological functions (e.g. the workings of memory) and among these there will be functions we associate with consciousness. For example, the function of bodily damage bringing us in an internal state that causes us to withdraw our hand form the fire, where we associate our internal state with being in the conscious state of feeling pain. The problem is that the neural mechanisms only concern the causal transactions among states and not the nature of the states themselves. That is, the description of how neurons function, fails to capture what is distinctive about pain, namely that it hurts. In other words, the relations captured by the neurological analysis do not claim anything regarding the very nature of our mind. Whatever mechanisms are revealed by research, have nothing to do with the actual state of "being" - the great and still unanswered question of philosophy of the self.

The above-mentioned issues are discarded by neuroscientists as irrelevant: Explaining things does not mean we can explain everything now, they counter-argue ${ }^{[4]}$. True. But isn't this an argument that can be invoked in favor of a non-materialistic explanation of the mind as well? In order to stay within the scope of scientific inquiry, consciousness must have some functional aspect and yet, every aspect of our conscious experience is not related to any function whatsoever. It is when we actually do nothing that we feel the most active, as Cicero once said. It is when we stand alone without doing anything that we discover our self. Should we totally discard one potential explanation simply because we like the other better? Whereas we have good reason to believe consciousness is a material phenomenon since it correlates so well with neural activity ${ }^{[4,5]}$, we also have reason to believe the material and the conscious belong to a different level as it will be described in the next section. 
"if mental phenomena are in fact nothing more than emergent properties and functions of the brain, their relation to the brain is fundamentally unlike every other emergent property and function in nature",

As David Chalmers (1995) stated, while cognitive neuroscience can explain how the brain enables informational processing of the mind, it is incapable of explaining the qualitative experience that accompanies it. No matter what knowledge we gain about the visual processing of color and how precisely we are able to describe it, the quality of sensory experience of red cannot be known unless experienced ${ }^{[9]}$. Analyze and describe the way we taste a peach in the best way possible; again, you will not be able to understand how a peach tastes until you actually eat one. Another attempt to counter reductionism comes from a broad category of theorists who look to the relatively new science of complexity, or emergence, to explain the brain's relation to the mind. Emergence theory holds that interactions between lower-order phenomena can give birth to higher-order phenomena with properties which cannot themselves be reduced to the lower-order interactions.

Consciousness is clearly an emergent property. The latest evidence is that there is no master site of consciousness or control in the brain. If that is the case, looking to the subatomic level is clearly a move in the wrong direction. It makes as much sense as trying to understand the properties of water by studying hydrogen and oxygen. Even though water emerges from the combination of the two, studying its components tells us little about water itself. Just as the wetness of water cannot be found in the hydrogen and oxygen molecules that constitute it, so the complex qualities of mind, like reason, decision-making, reflection, and emotion cannot be found in the behavior of our neurons. The advantage of this way of thinking is that while it does not deny the biological roots of mind, it nonetheless acknowledges the validity of higher orders of human experience ${ }^{[10]}$. And we should not forget about subjectivity, which is another major piece of the puzzle. No other emergent property (e.g. liquidity) has subjectivity ${ }^{[7]}$ and yet, subjectivity is an inherent (and important) part of human consciousness. Discarding that from the picture is wrong; every theory trying to account for consciousness should have a special place reserved for that notion which seems to be unique for conscious beings.

\subsection{There is more than explaining things bottom-up}

During the compilation of this paper, millions of neurons were working in my brain. Molecules used chemicals to transfer messages and everything in my brain was working to produce the result you (and not your neurons) see. At the same time, on another (higher) level, I was thinking about what to write next. I decided what to do, why I wanted to finish this article, why I was interested in the topic et cetera. Confusing what happens at a microscopic level with what decisions I make as a person at a higher level is another type of common error in analyzing consciousness only on the basis of neurological activity.

As Templeton prize-winning cosmologist George Ellis said, "The standard mistake that fundamentalists make is to posit a partial cause as the whole cause. Yes, the neurons are there. That's a partial cause of what's going on. What these neuroscientists are missing, though, is the top-down action in the brain, which is the part that gives life its actual meaning. And if you only choose to look from the bottom up you will never see that meaning. Think of a jumbo jet flying. The bottom-up view of why it flies is because the

\footnotetext{
${ }^{2}$ B. Allan Wallace, The Taboo of Subjectivity: Toward a New Science of Consciousness (Oxford: Oxford University Press, 2000), 136.
} 
particles are impacting the wing from below and moving a bit slower than the particles above the wing. The top-down version of why the plane is flying is because someone decided to build the plane, employed a lot of people to use computer aided design tools for the design of the plane and then a lot more people to build it. At the same level of why the plane is flying lies the fact that the pilot is sitting at the controls and is making it fly. Some physicists tend to miss this top down view. And it's the same with neuroscientists. To return to the flight analogy, they would say that all that is making the pilot fly is the firing of some neurons in his brain. But then they would be missing the fact that he had decided to be a pilot when he was a kid. He got enthusiastic about it; he worked to raise the money for his training and managed to overcome obstacles in his journey to fulfilling his dream. Neuroscience just messes all of that up; or just blatantly ignores them completely. It is unable to see those higher levels because it is focused on the lower levels ${ }^{[10]}$. The mind cannot be the same as the brain, because the mind also has a top-down causal influence on the brain. And this refers not only to examples of cognitive therapies exploiting neuroplasticity ${ }^{[7]}$, but more generally to the way our human free will (which is again discarded on the basis of adherence to specific philosophical dogmas) affects our life per se.

In other words, the mind can affect the brain and vice versa. And ignoring that reality is neither scientifically nor philosophically sound. The willful, mindful effort can alter brain function, and such self-directed brain changes are a genuine reality. All experience shows that the arrow of causation relating brain and mind is bidirectional ${ }^{[11]}$. Deliberately choosing to ignore one of the main potential directions of influence drastically limits the way we examine our mind. "The most striking feature is how much of mainstream [materialistic] philosophy of mind is obviously false.... In the philosophy of mind, obvious facts about the mental, such as that we all really do have subjective conscious mental states are routinely denied by many of the advanced thinkers in the subject." "Nowhere in the laws of physics or in the laws of the derivative sciences, chemistry and biology, is there any reference to consciousness or mind." 4

\subsection{The human memory problem}

The memory functionality of the brain is another problematic area which indicates potential gaps in our understanding. For example, much research has been conducted on animals from which scientists have removed large part of their brain, but they still continue to remember things they have learned ${ }^{[12,13,14]}$. When we remove a section of the brain which seems to be the one which holds the memories, another part of the brain takes on that role. Scientists removed surgically sections of the brain of chickens where they saw (via radioactive substances put into the brain) that some new tricks that those chickens had learnt were stored, but the chickens still remembered how to do the tricks ${ }^{[15]}$. Such results show that founding the functionality of the memory only on the material substrate of the brain may be missing important aspects of that functionality.

If memory is stored in the brain, then the cells or at least their structure should remain exactly the same for years in the sections where the memory is stored. But as we now know, this does not happen; research has shown that all the cells of the brain change constantly ${ }^{[16 \text {, }}$ $17,18,19]$. If the area of the brain which is related to learning is destroyed, then the brain recreates this region in another place ${ }^{[20]}$. What is more, the problems posed by brain

\footnotetext{
${ }^{3}$ John Searle, The Rediscovery of Mind (Cambridge, MA: MIT Press, 1992), 3.

${ }^{4}$ John Eccles and Daniel Robinson, The Wonder of Being Human: Our Brain and Our Mind (New York: Free Press, 1984), 37.
} 
plasticity research are not limited to memory. The cells of our brain change every day. How do we remain the "same" person if ever-changing matter is all that we base our existence upon? How can you interpret more easily this phenomenon, if not via admitting the existence of an immaterial "something" which resides outside the brain (or transcends the brain) and controls its material substance?

This is more than just a philosophical trick; it is something deeply related with the very nature of our self. And it should not be disregarded by science as something irrelevant. Even though modern scientists try to persuade us that philosophy is dead, in fact philosophy today is more relevant than ever. All things examined by science are in one way or another related to philosophy and the assumptions we make are related to specific philosophical opinions; knowing these opinions (and having the courage to question them) is crucial for scientists to understand the true nature of their theories.

\section{ARGUMENTS FOR A MORE IDEALISTIC VIEW OF THE MIND}

As scientists try to unlock the mysteries of consciousness, the old debate about monism-dualism comes into the surface. This section presents some arguments that could be used in favor of a more non-materialistic (idealistic) interpretation of the phenomena of the mind. Science tries to explain phenomena that are spiritual with tools that are specifically designed to unlock the mysteries of matter. If a scientific theory has the underlying dogma that no spirit exists, then how can it find spirit even if it is there? There is evidence which provide a hint towards what seems to be the right direction, but our compasses are calibrated so that they will never look that way. It is true that we cannot be certain of the nature of consciousness with the things we know now and that is exactly the point of this paper: to show that research on the topic must continue with a mind free of any dogmas and prejudice. All in all, the belief in the non-existence of spirit can be as dogmatic as the belief in the existence of spirit.

This more idealistic way of seeing the brain can take many forms. For scientists like Rupert Sheldrake, one of the most powerful explanatory tools for understanding the workings of life and mind is the physical notion of the "field", first introduced to science by Michael Faraday in the $19^{\text {th }}$ century. "From electromagnetic fields, to gravitational fields to quantum matter fields, these field theories have taken over physics in such a way that everything is now seen as energy within fields", according to Sheldrake. "As Sir Karl Popper put it, "Through modern physics, materialism has transcended itself, because matter is no longer the fundamental explanatory principle. Fields and energy are.' So then when we come to the mind and the brain, what if the brain is a system that's organized by fields as well?"[10]. In any case the simple question "What is a particle?" is not so self-evident or "materialistic" as it first seems. (See Consciousness and Quantum Mechanics section below) In general, explaining consciousness with energy fields is something that could provide a valid alternative that fits many of the properties of consciousness we see. And in any case, it should be noted that the point is not to prove anything, just to show that there are other possibly viable solutions to the problem under examination. For others, the non-materialistic nature of our consciousness could stem from modern quantum mechanics. There we have observed that the observer can affect the outcome of the experiment just by observing it (see below for double slits experiment analysis). This kind of effect to the outcome of the experiment is not possible by material interactions between particles. Could our consciousness be made of something non-materialistic as Neumann postulated? 
In summary, idealism and dualism have much less to account for than materialism. As Keith Ward said, unlike materialism, what other more idealistic explanations don't have to do is to explain away the personal experience of every human being. We are something that we all understand it to be something different than voltage or particles moving. And at the end that is the best argument in favor of a more spiritual view of the brain.

"No single brain area is active when we are conscious and idle when we are not. Nor does a specific level of activity in neurons signify that we are conscious. Nor is there a chemistry in neurons that always indicates consciousness."

\subsection{Function has many definitions}

The great philosopher William James argued that all the problems in brain research arise from the monolithic way in which we understand the function of the brain. Materialistic science - he said - can think of the brain function only in the "function that produces something" way. However, "function" can have other meanings as well. Many things function in a way to "allow things to happen", like when your hand pulls a trigger so as to remove the barrier holding the gun to go off. Function could also mean "function to allow transmission of things", like a colored glass (the function of which is to allow the transmission of light through it). The brain could act in one of the other two ways of "function", thus being simply a way to allow souls to manifest themselves in this world ${ }^{[21]}$. (Remember the TV analogy described above)

This is a very interesting alternative in interpreting data, which all scientists dealing with the problem of the brain should always have in mind. The definitions we use could sometimes affect the result we get. And as Aristotle said, the questions almost always include the answer; researching for the mind into the brain via matter-based questions makes it certain that no mind will ever be discovered. Researching for the generating function of the brain regarding consciousness makes it certain that there is no possibility to discover any other potential functions it may possess. All the above is important, but they seem even more crucial if one takes into account that modern science has a very frightening record of imposing specific definitions on things which can be defined in many other ways.

\subsection{Consciousness and Quantum Mechanics}

An interesting debate is going on related to quantum mechanics and the possible role of human consciousness on the result of a measurement ${ }^{[2]}$. The 'mystical' wave function produces a set of possibilities that all exist simultaneously (a phenomenon known as quantum superposition). One of the quantum mechanics interpretations claims that only when a human observer observes the particle, does the function collapse to a single "reality". This interpretation states that the "thing" that actually causes the wave function to collapse is the consciousness of the human observer. This is also known as the Von Neumann-Wigner interpretation ${ }^{[23]}$. This theory solves many problems of quantum mechanics. Consider for example the double slit experiment. The electron actually "chooses" to be a wave or a particle only after the measurement/ observation. But what is "observation"? Many scientists have published papers which examine the role of consciousness in the collapse of the wave function ${ }^{[24]}$ and it seems that the possibility that consciousness actually causes the electron to "decide" is an explanation one cannot simply ignore. Many people believe that Wigner's

\footnotetext{
${ }^{5}$ Mario Beauregard and Denyse O'Leary, The Spiritual Brain: A Neuroscientist's Case for the Existence of the Soul (New York: HarperCollins, 2007), 109
} 
interpretation is old and, thus, outdated. But such an argument is fundamentally flawed: being old does not necessarily mean that something is wrong in any case (if such was the case we should have stopped reading Parmenides, Aristotle and Plato a long time ago). It is true that this is just one of the multiple potential interpretations of quantum mechanics; currently more than ten are still active ${ }^{[25]}$. But it is the most philosophically sound. First of all, this interpretation is totally mathematically compatible with the results ${ }^{[26]}$. So, we cannot discard it on the basis of non-conformance with the experimental data. The only reason physics today discard this interpretation, is its opposition to the classical physics model that "reality" exists somewhere independently from us (another assumption which has turned into dogma). Wigner actually shifted to those interpretations (and away from the idea that consciousness causes collapse) in his later years. And it is important to note that this did not happen because the interpretation proved wrong (in any case can that ever happen for an interpretation? - another interesting question) but partly because he was embarrassed that the "consciousness causes collapse" idea can lead to a kind of solipsism ${ }^{[27]}$. What is more, no other interpretation can explain why the wave function does not collapse before the observation. If one considers observation to simply be the interaction with the measurement instruments (i.e. the interaction of non-living matter with other non-living matter), then why does the electron not collapse to a specific state due to its interaction with all the other physical elements of the experiment setting? What makes the "measurement" special? How is the measuring device different from any other material in the experimental device? (the air, the cosmic radiation, the other particles, the numerous fields existing in the experiment site and so on). The answer is - according to modern physics - that essentially it is not different at all. But then, many philosophical problems arise. Could this mean that any experiment regarding the collapse of the particles' wave function could be conducted via interaction with anything? In the double slit experiment, no interaction with the gravity field, with electromagnetic fields or with other particles in the air results in the collapse - only when a human observer observes do we have that collapse. Something similar to the above experiments and equally important is observed in the Quantum Zeno effect in which an unstable particle, if observed continuously, will never decay ${ }^{[28]}$. It is also important to note that the double slit experiment shows not only that the observer affects the thing observed, but that the effect of the observer traces back in time, as in the Wheeler's delayed choice experiment ${ }^{[29][30]}$. This adds additional problems to the attempt to explain these experiments via a strictly materialistic interpretation - matter affects matter only forward in the direction of the arrow of time. Some counter-argue that the abovementioned interpretation is not falsifiable. This could be true in a sense: there is no way to observe the result of an experiment without anyone observing the result anyway. But this is also an argument against other interpretations which ignore the effect of consciousness on the result: how can you determine there is no such effect if you haven't conducted any experiment without that element in the experiments you conduct? What is more, we must remember that falsifiability does not guarantee the validity of a theory; it is just a criterion we would like to have in place to make our work of analyzing the alternatives easier. It is nice to have, but not necessary to make a theory scientific or valid. How falsifiable are for example other (seemingly more valid for modern physicists) interpretations, like the multiverse theory which calls for the instant creation of a new universe every nanosecond that a wave function collapse takes place? All in all, the conscious observer seems to affect the cosmos and reality. This is something accepted or heavily discussed among scientists today. The cat 
seems to be both dead and alive until an observer observes it. And the current way science thinks, is not compatible at all with the above-mentioned observations.

\subsection{Non-local consciousness \& Near-Death Experiences (NDE)}

Research from known scientists and universities has shown that consciousness may not be an exact synonym to brain functions through providing strong indications that the link between consciousness and the brain might not be as tight as we might think. Even though such research and conclusions are often discarded as pseudoscience, it must be noted that prestigious scientists or institutions are involved in it. And although it is true that the use of such research results by pseudoscience proponents is a problem that does exist, it must be noted that the pseudoscience problem is not limited only to consciousness research; screening of the validity of a source and logical analysis of the conclusions presented is something which is always needed in all fields of science (and for all conclusions, atheisticfriendly conclusions included).

Research regarding non-local consciousness has been conducted by the Princeton University and reached impressive conclusions ${ }^{[31]}$. The Princeton Engineering Anomalies Research (PEAR) program, which flourished for nearly three decades under the aegis of Princeton University's School of Engineering and Applied Science, discovered many empirical anomalies which are inconsistent with the established models of our era. As the university official page claims, "PEAR's contribution to this expansion of the scientific worldview has been its accumulation of huge bodies of consciousness-correlated empirical evidence that the subjective/ objective dichotomy of Cartesian philosophy is no longer entirely viable". One of the implications of that research is that "accommodation of these anomalies within a functional scientific framework will require the explicit inclusion of consciousness as an active agent in the establishment of physical reality" (sic). The implications of consciousness in quantum mechanics discussed above is a similar example of how our consciousness seems to affect things outside the limitations of our body.

Near-death experience (NDE) is another field which shows promising leads towards a non-materialistic view of the cosmos. They were first reported by Dr. Pirn van Lommel in a prestigious scientific journal, the medical journal "The Lancet" ${ }^{[32]}$. NDEs are perhaps the most intriguing challenge to the neuroscientific mainstream view and more data is emerging from a growing body of related research. Throughout the ages and across cultures, people have reported a variety of mystical phenomena surrounding the dying process. But with the technological explosion of the twentieth century, one medical advance in particular has opened a significant window into the phenomenology of dying - namely, our ability to resuscitate people, to bring them back from the dead.

It is easy to understand why these experiences have such a profound psychological and spiritual impact. And that, along with the fact that exploring the borders of life and death is so difficult, is the reason why objections to the validity of NDE experiences are not few. Reports of NDEs are often discarded by the scientific community as hallucinations; they do not fit at all with the current picture drawn by the current scientific theories. As neuropsychiatrist and renowned near-death researcher Peter Fenwick points out, "the simple fact that people have these experiences does not in itself prove anything one way or the other regarding the existence of consciousness outside the brain". Simply put, how do we know the NDE is not just a brain-generated illusion? According to the "dying brain hypothesis" as put forward by psychologist Susan Blackmore, all the specific phenomena associated with the classic NDE can be accounted for by established brain responses to the "severe stress, 
extreme fear, and cerebral anoxia" that would naturally accompany a brush with death. But riddled throughout the NDE literature are accounts that seem to suggest that there is more going on in these experiences than what can fit into the materialist picture of a simple hallucination. Besides the Lommel paper, there are many other papers discussing similar incidents reported in literature. And not all of them can be easily discarded ${ }^{[33]}$. For example, eminent cardiologist Fred Schoonmaker conducted an 18-year study of 1,400 near-death experiences, including those of about 55 persons whose experiences took place while flat EEG readings were recorded ${ }^{[34]}$. Prospective studies, reviewed groups of individuals and then found out who had an NDE. In general, close to 3,500 individual cases between 1975 and 2005 had been reviewed in one or another study by more than 50 researchers or teams of researchers ${ }^{[35]}$. The International Association for Near-death Studies (IANDS) holds conferences, at regular intervals, on the topic of near-death experiences. The first meeting was a medical seminar at Yale University, New Haven (CT) in 1982. Since then conferences have been held in major U.S. cities, almost annually ${ }^{[36]}$. Many universities also continue to carry out research related to the matter ${ }^{[37]}$. On the whole, there are strong scientific indications that consciousness is something which survives the physical death of the body. And if we follow the falsification logic of Popper, the validity of only one of these cases would suffice to discard the whole materialistic theories of the brain.

Additionally to the above, even more startling indications that materialism may be wrong come from cases where humans appear to have a normal life even though they do not have a normal brain (at least in the way we define it). The research of John Lorber is the most famous example. In 1980, Roger Lewin published an article in Science about Lorber's studies on cerebral cortex losses. In that he reported the case of a Sheffield University student who had a measured IQ of 126 and passed a Mathematics Degree but who had hardly any discernible brain matter at all since his cortex was extremely reduced by hydrocephalus ${ }^{[38]}$. For an instrument that is so delicate that even the slightest problem might result in turning into a plant or dead, having example of people who function perfectly with most of their brain missing is surely the counter-example needed to start thinking whether we took the wrong turn.

All of the above have led prominent researchers, such as the late Nobel-winning neuroscientist Sir John Eccles, to propose a dualist view of the problem, arguing that the human mind and consciousness may in fact constitute a separate, undiscovered entity apart from the brain ${ }^{[39]}$.

\subsection{Zombie arguments}

Other arguments in favor of a less materialistic view of consciousness are related to what we feel every day: that we "are" ourselves and not a set of machinery working. Our brain is not a set of electrons, because a set of electrons is just "a set of electrons", not a thinking entity. We are not zombies ${ }^{[40]}$, we are thinking human beings doing more than just feeling and reacting according to physical laws without being conscious of what we do ${ }^{[41]}$.

If physicalism was right and if indeed everything we did could be explained by the action-reaction mechanistic model of our body, then there would be no room for what we feel and "know" that we have: that "something" which makes us humans, which makes us more than simple reacting machines. We know that we do not just react to things like zombies. We know that we do not just live according to automated processes and physical laws. We know that we are who we are. I know that it is "I" who speaks and not the physical laws governing the electrons in my brain. I know that I am the one writing now and not the 
physical laws governing the universe. I know that I have free will and that what I write here is "mine" (and not product of a machine in the form of a human body with no intellect or consciousness), as you also know that what I write here is "mine". You may even write a comment to "me" complaining about what I wrote. Last but not least, we all understand that others we interact with are not zombies as well; they are conscious beings functioning according to what they decide and feel like. Not in a single moment do we think of the possibility that other human beings are just zombies (or robots); so how can a theory which actually defends such a view be considered so self-evident? In our everyday life we constantly adhere to the non-materialistic view of the mind, in how we behave towards our self and towards others. This might not look as "scientific", but perhaps it is more valid that any scientific view on the matter - especially because it is not (scientific in the strict sense of the word). Modern science seems to have difficulties to account for the simple things humans feel and it seems that we all need a more spiritual point of view to guide science back to us. After all, every scientific theory must adhere to the empirical data we have available. And this is a great chunk of data we seem to deliberately ignore.

\section{THE NEED FOR A MORE SPIRITUAL SCIENCE}

All contemporary neuroscience is based on classical physics. No surprise it supports the view of the self which is based on the brain and a set of mechanical laws. That is the only view that type of physics can come up with. It cannot explain how consciousness arises since there is simply no consciousness in classical physics; it was erased from the study of matter by Descartes' dualism (i.e. that mind and matter are separate). And it was on these foundations that Newton erected classical physics, the science of matter, which does not deal with mind in any form. By definition, Descartes's dualism predicts that mind cannot be explained from matter, and Newton's physics is an expression of dualism. Modern physics tries to examine reality as something existing "objectively" somewhere out there. And this objective reality does not have room for subjects (conscious humans). Neuroscientists are looking for consciousness based on tools which cannot detect consciousness by design ${ }^{[42]}$.

However, it would be unfair to say that science has inherent limitations. It is not that the methods and institutions of (empirical) science somehow compel us to accept a materialistic explanation of the phenomenal world, but that we are forced into that path by our a priori adherence to material causes and axioms ${ }^{[43]}$. Modern science seems determined not to look for the source of consciousness anywhere else but in matter. But only a bad detective argues "The murderer can't be in the basement - because I'm afraid to look there". Some materialists admit that materialism cannot be shown to be valid a priori. Instead, they claim that since materialism has had such an impressive track-record in solving problems, we must assume it will continue to succeed. But this is plainly wrong. Materialism does not have an impressive track-record in explaining things at all. It was Christian theology, not materialism, which gave birth to modern science. Great scientists such as Newton, Kepler and Galileo tried to find the physical laws governing the universe in an attempt to unravel God's master plan of the cosmos. The need to read the "mind of God" was the philosophical stone which drove all scientific efforts during the time of Newton.

What is more, materialism inherently conflicts with the rationality of science: The dogma "in the beginning there was nothing, then nothing created something and now we only have some electrons and protons moving around randomly" cannot explain the existence of all-powerful universal physical laws or the emergence of the patterns we see. Theism on the other hand supports that rationality: The existence of universal physical laws 
can be explained by the theory of a First Cause or a great Designer who actually put in place those laws. And the failure of materialism to account for the mind (as described above) is one of the most staggering examples of how dogmas can hinder the progress of science if we fail to see them ${ }^{[7]}$. Regarding the mind, it seems that the materialistic dogma cannot explain the subject-object (human-matter) relationship, the way we think or - more importantly - the very essence of what we feel as "beings". The notion of spirit - at least as potential explanation framework - must be embedded again in the science of the mind if we are to discover our true self. Taken together, alternative non-materialistic theories seem to present a formidable case for the scientific establishment to reckon with. But the materialistic bias in western science runs deep. And just how exactly it will be overturned remains anybody's guess. Regardless of the when this will happen, it seems that the thinking of modern science regarding the nature of the mind/body problem is a turning point we will eventually face. As futurist and popular science author Peter Russell suggests in 'From Science to God', "I now believe this is not so much a hard problem as an impossible problem - impossible, that is, within the current scientific worldview".

According to Popper, science progresses through the falsification of current theories and the formulation of new ones. And it takes only one counter-example, only one exception, to change the theory. You may have observed thousands of white swans and believe that you have a very solid case for the "All swans are white" theory, but it only takes one black swan to tear the theory down to the ground. In the case of mind research, it seems that many black swans are trying to fly in front of us, but we just won't let them.

\section{OUR IDENTITY: CONSCIOUS BEINGS IN A MATERIAL COSMOS}

Humans have been searching for the meaning of life and their identity in the universe since they started thinking. From the beginning of mankind, we were seeking our purpose in life. We were seeking our soul in the world and most of us believed that we had one. We could understand we were inherently different than a rock, but at some point, we attempted to analyze the nature of that difference. And that was when we forgot what we knew regarding our self.

Our journey in science has drifted us away from the wisdom we once had. Because we chose to transform wisdom into knowledge. And this sin, often mixed with arrogance, made us blind to what was once crystal clear to all of us: That we exist as persons. Every scientific advancement has drifted us away from the self-evident truth that "I am" - every experiment and every scientific announcement was based on the assumption that the universe is made only from matter and, thus, consciousness as a spiritual force has no place here. The fruit of knowledge has cast us away from the "paradise" of believing into our self; we now see us in the mirror only as an elaborate illusion. Modern advancements in science, which turned that knowledge into simple data, just made things worse. Nowadays scientists keep on analyzing data in the context of existing scientific models; thus, not allowing any room for doubt on whether the initial assumptions are still valid or not.

Nevertheless, all axioms and assumptions should someday be questioned. And the research on the matters of mind has generated so many questions that the time is right to raise the alarm that we could be building castles on sand. As quantum physics has showed, the observer is no longer a mindless being with no will, but the one who actually decides what will be seen. Consciousness has been transformed from a "result of matter" to a "source of reality". Even the once thought structural components of matter - particles - are now considered to be probability waves the existence of which depends on interaction with 
beings with consciousness. In this sense the atoms are more like "ideas" than spheres travelling into space. Neuroscience's attempts to solve the problem of consciousness could be - potentially - the reason why science will need to admit that it is reaching a dead-end. The secrets of the mind are not an inch closer to decrypting, despite all the phenomenal progress in data analysis concerning brain functions. Mind is not the slave of matter, but its master. And it seems that modern science will soon shift to a new paradigm and towards more holistic forms of thinking. As Chomsky postulated, our identity problem in the form of the Mind-Body controversy, can be solved in an innovative way if we consider modern scientific findings differently: There is no body! We are not specks of dust. We are important. We are the ones who give life to the universe itself. But if we want we can be unimportant. At the end, it is a matter of (conscious) choice.

"The culture of popular science is one of unidirectional skepticism... It is skeptical of any idea that spirituality corresponds to anything outside ourselves, but surprisingly gullible about any reductionist explanation of it."

\section{CONCLUSION}

Humans have for a long time postulated on the great questions of "Who am I". And even though initially the existence of consciousness as spiritual force was common knowledge, as centuries passed humans destroyed that notion on the basis of nihilistic assumptions. Now science stands at a turning point, where our inability to account for consciousness seems to be the trigger that will, in time, push western science into what the American philosopher Thomas Kuhn called a "paradigm shift". Science's failure to solve the mind-body problem could ultimately be materialism's undoing. True scientists should be open to different interpretations and current experimental data strongly indicate that there is more than meets the eye in the world. The notion of 'spirit', initially discarded by modern science as unscientific, makes its way back, although not in the near future. It is difficult to discard assumptions which hold for thousands of years, especially when these assumptions are the basis of all current research community activities. Despite all that, at the end humans will remember who they are and regain their identity, coming in harmony with the reality of being conscious. Because no matter how many things neuroscience will discover for the functions of the brain, a different reality follows us every day and every passing minute: It is not my brain which wrote this article. It is me.

\section{BIBLIOGRAPHY:}

[1] Thomas M Bartol Jr, Cailey Bromer, Justin Kinney, Michael A Chirillo, Jennifer N Bourne, Kristen M Harris, Terrence J Sejnowski, "Nanoconnectomic upper bound on the variability of synaptic plasticity", eLife, Nov 30, 2015, DOI:10.7554/eLife.10778

[2] Popular Science, "The Human Brain Could Store 10 Times More Memories Than Previously Thought", retrieved from https://www.popsci.com/human-brain-could-store-10-times-more-memories-thanpreviously-thought on 10/1/2018.

[3] Jianjun Meng, Shuying Zhang, Angeliki Bekyo, Jaron Olsoe, Bryan Baxter, Bin He, "Noninvasive Electroencephalogram Based Control of a Robotic Arm for Reach and Grasp Tasks", Scientific Reports, 2016; 6: 38565 DOI: 10.1038/srep38565.

[4] Jakob Hohwy, "Consciousness", Department of Philosophy, Monash University, Polimetrica Onlus, November 6 2007, retrieved from http://www.polimetrica.eu/site/?p=131 on 06/2008.

[5] Jakob Hohwy, Chris Frith, "Can Neuroscience explain Consciousness?", Department of Philosophy, Monash University, Journal of Consciousness Studies, 11, No 7-8, 2004, pp 180-198.

\footnotetext{
${ }^{6}$ Mario Beauregard and Denyse O’Leary, The Spiritual Brain, 91.
} 
[6] Dr. Robert Lawrence Kuhn, “Can Brain Explain Mind?”, retrieved from http://scienceandreligiontoday.blogspot.gr/2009/01/can-brain-explain-mind.html at 12/01/2018.

[7] Jonah Lehrer, "Ramachandran on Consciousness", The Frontal Cortex, October 6 2006, retrieved from $\mathrm{http} / / /$ scienceblogs.com/cortex/2006/10/06/ramachandran-on-consciousness/ on 12/01/2018.

[8] Craig Hamilton, "Neuroscience, Consciousness, and the Soul", "Science and Religion: Global Perspectives", June 4-8, 2005, USA, Retrieved http://www.metanexus.net/archive/conference2005/pdf/hamilton.pdf on 12/1/2018

[9] Repovš, G, "Cognitive neuroscience and the 'Mind-body problem"”. Horizons of psychology. 13(2), 916,2004

[10] Dr. Angus, J. L. Menuge, “Does Neuroscience Leave Room for God?”, Concordia University, Wisconsin, debate with Dr. PZ Myers at University of Minnesota at Morris, April 19th, 2008.

[11] Jeffrey M. Schwartz, Sharon Begley, “The Mind and the Brain”, ReganBooks, 2003, pp. 94-95.

[12] Boycott, B. B., "Learning in Octopus vulgaris and other cephalopods", Pubbl. Stn. Zool. Napoli, 1954, 25:67-93.

[13] Boycott, B. B., and J. Z. Young. 1955, “A memory system in Octopus vulgaris”, Lamarck. Proc. R. Soc. Lond. B Biol. Sci.143:449-480.

[14] M. J. Wells, "Octopus: Physiology and Behaviour of an Advanced Invertebrate", University of Cambridge, Springer Science, 1978.

[15] Rupert Sheldrake, "The Presence of the Past: Morphic Resonance and the Habits of Nature", March 1, 1995, p. 165.

[16] Will Storr, "Can You Think Yourself Into A Different Person?", Huffington Post, 18/11/2015, Retrieved from https://www.huffingtonpost.com/entry/neuroplasticity_us_564cdeefe4b00b7997f8d10e on $13 / 01 / 2018$.

[17] Jennifer Warner, New Clues on Brain's Ability to Learn, WebMD Health News, reviewed by Laura J. Martin MD, April 04, 2011, Retrieved from https://www.webmd.com/brain/news/20110404/new-clueson-brains-ability-to-learn on 14/01/2018.

[18] Michelle W. Voss, Ruchika S. Prakash, Kirk I. Erickson, Chandramallika Basak, Laura Chaddock, Jennifer S. Kim, Heloisa Alves, 1 Susie Heo, Amanda N. Szabo, Siobhan M. White, Thomas R. Wójcicki, Emily L. Mailey,Neha Gothe, Erin A. Olson, Edward McAuley, Arthur F. Kramer, Plasticity of Brain Networks in a Randomized Intervention Trial of Exercise Training in Older Adults, Front Aging Neurosci. 2010; 2: 32

[19] Clare Wilson, New cache of fresh neurons found in human brains, New Scientist, 20 April 2014, Retrieved from https://www.newscientist.com/article/dn25096-new-cache-of-fresh-neurons-found-inhuman-brains/\#.UwZvZzOTuM8 on 14/01/2018.

[20] Moriel Zelikowsky, Stephanie Bissiere, Timothy A. Hast, Rebecca Z. Bennett, Andrea Abdipranoto, Bryce Vissel, and Michael S. Fanselow. Prefrontal microcircuit underlies contextual learning after hippocampal loss. PNAS, May 15, 2013 DOI: 10.1073/pnas.1301691110.

[21] William James, "Human Immortality: Two Supposed Objections to the Doctrine", Ingersoll Lecture, 1897.

[22] Measurement in quantum mechanics, Wikipedia article, retrieved from http://en.wikipedia.org/wiki/Measurement_in_quantum_mechanics on 12/01/2018.

[23] Von Neumann-Wigner interpretation, Wikipedia article, retrieved from https://en.wikipedia.org/wiki/Von_Neumann\%E2\%80\%93Wigner_interpretation on 12/01/2018.

[24] Dick J. Bierman, University of Amsterdam, "Does consciousness collapse the wave function", Mind and Matter1-1, Nov. 2003, Retrieved from https://arxiv.org/ftp/physics/papers/0312/0312115.pdf on $13 / 01 / 2018$.

[25] [Interpretations of quantum mechanics, Wikipedia article, retrieved from https://en.wikipedia.org/wiki/Interpretations_of_quantum_mechanics on 14/01/2018.

[26] F. London and E. Bauer, "La théorie de l'observation en mécanique quantique" (1939), English translation in Quantum Theory and Measurement, edited by J.A. Wheeler and W.H. Zurek, Princeton University, Princeton, 1983, pp. 217-259.

[27] Michael Esfeld, (1999), Essay Review: Wigner's View of Physical Reality, published in Studies in History and Philosophy of Modern Physics, 30B, pp. 145-154, Elsevier Science Ltd.

[28] Sudarshan, E. C. G.; Misra, B. (1977). "The Zeno's paradox in quantum theory". Journal of Mathematical Physics. 18 (4): 756-763. DOI:10.1063/1.523304.

[29] Helmut Schmidt, "The Strange Properties of Psychokinesis", Journal of Scientific Exploration, Vol. 1 No. 2, 1987, retrieved from http://www.fourmilab.ch/rpkp/strange.html on 13/01/2018. 
[30] John Archibald Wheeler, The "Past" and the "Delayed-Choice" Double-Slit Experiment, Mathematical Foundations of Quantum Theory, 1978, Pages 9-48.

[31] Princeton Engineering Anomalies Research project, http://www.princeton.edu/ pear/, retrieved at 16/01/2018.

[32] Dr Pirn van Lommel MD, Ruud van Wees PhD, Vincent Meyers PhD, Ingrid Elfferich PhD, "Neardeath experience in survivors of cardiac arrest: a prospective study in the Netherlands", The Lancet, Volume 358, Issue 9298, 15 December 2001, Pages 2039-2045.

[33] Chris Carter, "Science and the Near-Death Experience: How Consciousness Survives Death", Inner Traditions, August 2010.

[34] Audette, J. (1979). Denver cardiologist discloses findings after 18 years of near-death research. Anabiosis [East Peoria] 1(1), 1-2.

[35] Holden, Janice Miner; Greyson, Bruce; James, Debbie, eds. (Jun 22, 2009). "The Field of Near-Death Studies: Past, Present and Future". The Handbook of Near-Death Experiences: Thirty Years of Investigation. Greenwood Publishing Group. pp. 1-16. ISBN 978-0-313-35864-7.

[36] IANDS Fact Sheet, Retrieved from https://iands.org/about/about-iands27/fact-sheet.html on $16 / 01 / 2018$.

[37] University of Virginia School of Medicine, Research on Near Death Experiences section, Retrieved from https://med.virginia.edu/perceptual-studies/research-area/near-death-experiences-ndes/ on $16 / 01 / 2018$.

[38] Roger Lewin (12 December 1980). "Is Your Brain Really Necessary?". Science. 210 (4475): 12321234, DOI:10.1126/science.7434023.

[39] J. Allan Hobson, MD, "Neuroscience and the Soul: The Dualism of John Carew Eccles", April 01, 2004.

[40] Philosophical zombie, Wikipedia from https://en.wikipedia.org/wiki/Philosophical_zombie on 13/01/2018.

[41] Dennett, Daniel, "The unimagined preposterousness of zombies", Journal of Consciousness Studies, 1995, 2: 322-6.

[42] Piero Scaruffi, "Thinking about Thought 4 - Consciousness", Amazon Digital Services LLC, 2014.

[43] Beauregard M, "Mind does really matter: evidence from neuroimaging studies of emotional selfregulation, psychotherapy, and placebo effect”, Prog Neurobiol. 2007 Mar; 81(4):218-36. Epub 2007 Feb 9. Review, PMID: 17349730. 